clinicians in the following hospitals for allowing us to study their patients: Chelsea and Westminster, Hillingdon, Central Middlesex, North Middlesex, West Middlesex, Milton Keynes, Northampton General, Northwick Park, Royal Free, and Watford General. Thanks to R Booy for fruitful discussions.

Contributors: JNW, MOMcC, JAE, and SW set up and have monitored the infant HIV diagnostic service. JNW and GT-W were the instigators of this paper. EGHL wrote the paper and CS, GPT, JNW, MOMcC, SW, and GT-W took part in its editing. $\mathrm{CS}, \mathrm{MA}-\mathrm{K}$, and SB carried out laboratory testing of the infants and mothers. EGHL, GPT, and CS collated the results; Paula Seery collated results from the Chelsea and Westminster Hospital. Contributors from the clinical paediatric service were SW, GT-W, JAE, Stephen Marriage, and EGHL; contributors from the clinical adult service were GPT, Siobhan Crowley, and AW; contributors from obstetrics and midwifery were Ms S Dick, Ms M Hornby, Ms F Clayton, and Mr J Smith. Other clinicians from surrounding hospitals who referred their patients also contributed clinically (see acknowledgements). The guarantor is Hermione Lyall.

Funding: No additional funding.

Conflict of interest: None.

1 Connor EM, Sperling RS, Gelber R, Kiselev P, Scott G, O'Sullivan MJ, et al for the Paediatric AIDS Clinical Trials Group Protocol 076 Study
Group. Reduction of maternal-infant transmission of HIV-1 with zidovudine treatment. N Engl J Med 1994;331:1173-80.

2 Centres for Disease Control. Public Health Service task force on use of zidovudine to reduce perinatal transmission of human immunodeficiency virus. MMWR 1994;43(RR-11):1-21.

3 Fiscus SA, Adimora AA, Schoenbach VJ, Lim W, Mckinney R, Rupar D, et al. Perinatal HIV infection and the effect of zidovudine therapy on transmission in rural and urban counties. JAMA 1996:275;1483-8.

4 Blanche S, Mayaux MJ, Mandelbrot L, Rouzioux C, Delfraissy JF for the French Pediatric HIV Infection Study Group. Acceptability and impact of zidovudine prevention on mother to child HIV-1 transmission in France [abstract]. 4th International Conference on Retroviruses and Opportunistic Infections, Washington, DC, 1997.

5 National Institute of Child Health and Human Development. Pediatric ACTG protocol 185. Executive summary. Bethesda, MD: National Institutes of Health, 1997.

6 Department of Health. Unlinked anomymous HIV prevalence monitoring programme: England and Wales. Data to end 1995. London: DoH, 1996.

7 Gibb DM, MacDonagh SE, Tookey PA, Duong T, Nicoll A, Goldberg DJ, et al. Uptake of interventions to reduce mother-to-infant transmission of HIV in the United Kingdom and Ireland. AIDS 1997;11:F53-8.

8 McClure MO, Bieniasz PD, Weber JN, Tedder RS, O'Shea S, Banatvala JE, et al. HIV clearance in an infant? Nature 1995;375:637.

9 Sperling RS, Shapiro DE, Coombs RW, Todd JA, Herman SA, McSherry GD, et al. Maternal viral load, zidovudine treatment, and the risk of transmission of HIV-1 from mother to infant. N Engl J Med 1996;335:1621-9

\title{
Antenatal HIV testing: current problems, future solutions. Survey of uptake in one London hospital
}

\author{
Teresa A Duffy, Charles D A Wolfe, Claire Varden, Jane Kennedy, Ian L Chrystie, Jangu E Banatvala
}

See editorial by

Mercey

Department of

Midwifery, Guy's

and St Thomas's

NHS Trust, St

Thomas's Hospital,

London SE1 7EH

Teresa A Duffy,

research midwife

Jane Kennedy,

midwife counsellor

Public Health

Medicine, United

Medical and Dental

Schools of Guy's

and St Thomas's

Hospitals, London

SE1 7EH

Charles D A Wolfe,

senior lecturer

Claire Varden,

assistant statistician

Department of

Virology, United

Medical and Dental

Schools of Guy's

and St Thomas's

Hospitals, London

SE1 7EH

Ian L Chrystie,

lecturer

Jangu E Banatvala,

professor of clinical

virology

Correspondence to: Professor Banatvala

BMJ 1998;316:270-1
Pregnant women attending Guy's and St Thomas's Hospitals Trust have one of the highest prevalence rates for HIV-1 in inner London (0.53\% in 1996). ${ }^{1}$ In 1992 we showed that this was associated with African ethnic origin. ${ }^{2}$ However, despite the Department of Health's recommendations that named HIV testing be made available to all pregnant women in areas of relatively high prevalence, uptake in our trust is disappointingly low-about 30\%-as elsewhere in inner London. In 1995, throughout London, only 26 of 205 (13\%) HIV positive pregnant women had been identified antenatally. ${ }^{3}$ Most were therefore almost certainly unable to benefit from recent advances in treatment and in the prevention of mother to child transmission of HIV.

\section{Subjects, methods, and results}

This paper describes uptake of HIV testing among pregnant women between 1991 and 1996 and includes a detailed survey of 789 women, of whom 428 attended antenatal clinics at Guy's Hospital, 310 attended six community clinics, and 51 attended a midwifery group practice between 5 March and 20 December 1996. Of the antenatal population, $50 \%$ were white, $24 \%$ were black African, and 13\% were black Caribbean. Before booking, women were sent a locally produced leaflet about HIV. At booking, midwives-49 of $51(96 \%)$ of whom had had specific training about HIV-initiated a pretest discussion, and before and after booking women were invited to complete questionnaires relating to attitudes towards HIV testing.

Although 35\% of 789 women accepted the offer of an HIV test, over a third of those who had intended to be tested changed their mind during the booking interview; only a few of those not intending to be tested did so (table). Multivariate analysis showed that being non-white was a significant predictor of uptake $(\mathrm{P}=0.044)$ and that uptake was higher in the hospital based clinic (41\%) than in the community clinic (30\%) or midwifery group practice $(10 \%)(\mathrm{P}=0.0001)$.

\section{Comment}

Since the start of antenatal HIV testing in 1985, uptake at St Thomas's Hospital has risen from 5\% to about $30 \%$. In 1992-4, of those identified on a named basis, $14 / 18(78 \%)$ were identified via the genitourinary medicine clinic; in 1995-6, 19 of 32 (65\%) were identified in antenatal clinics.

Although our results may seem disappointing in terms of uptake, the value of midwifery staff trained in HIV is emphasised by differences in HIV detection rates between Guy's and St Thomas's Hospitals before their unification in 1995. Between 1991 and 1995, Guy's, which had no midwifery staff trained in HIV, failed to identify any of the HIV positive pregnant women identified by the Public Health Laboratory Service's unlinked anonymous survey; at St Thomas's, however, which had an HIV specialist midwife counsellor and trained staff, 39 of $105(37 \%)$ were identified.

Merely achieving higher uptake rates may not increase the proportion of women positive for HIV-1 identified, as many may decline testing. Indeed, in the past 8 months, we know of three pregnant women who knew they were HIV positive at booking but declined testing without divulging their serostatus. 
Britain is lagging behind other European countries and some American states in detecting HIV positive pregnant women. ${ }^{4}$ Furthermore, even in locations such as ours, where current Department of Health recommendations are being implemented, uptake is disappointingly low. As a matter of urgency, multidisciplinary research needs to be directed towards discovering why pregnant women seem to feel that the social consequences of being identified as HIV positive outweigh the advantages of high quality management for mother and baby. In the meantime the Department of Health should strongly support the recommendations of the Intercollegiate Working Party for Enhancing Voluntary Confidential HIV Testing in Pregnancy, and consideration should be given to implementing an opt-out approach to HIV testing, as approved by the working party of the Institute of Medical Ethics in 1990.5

We thank colleagues involved in the European study on antenatal HIV testing-policies and procedures (EU grant SOC 95200587 05F202) for their help.

Contributors: Each of the authors has been involved in the ongoing investigations of antenatal HIV testing at Guy's and St Thomas'Trust and participated in the design of the 1996 uptake study. TAD with the assistance of JK carried out that study, with statistical analysis being coordinated by CV and CDAW. ILC and JEB collated and analysed the 1991-6 uptake data. The paper was written jointly by ILC and JEB with input from the other authors.
Intention to take HIV test before and after prebooking discussion. Values are numbers (percentages)*

\begin{tabular}{|c|c|c|c|c|c|}
\hline & & \multicolumn{4}{|c|}{ After discussion with midwife } \\
\hline & & Yes & No & Don't know & Total \\
\hline \multirow{4}{*}{$\begin{array}{l}\text { Before } \\
\text { discussion } \\
\text { with } \\
\text { midwife }\end{array}$} & Yes & $206(64)$ & $70(22)$ & $44(14)$ & 320 \\
\hline & No & $13(5)$ & $238(90)$ & $12(4)$ & 283 \\
\hline & Don't know & $51(26)$ & $90(46)$ & $54(28)$ & 195 \\
\hline & Total & $270(35)$ & $398(51)$ & $110(14)$ & 778 \\
\hline
\end{tabular}

*Some questionnaires were not completed fully.

Funding: Lambeth, Southwark, and Lewisham Health Authority.

Conflict of interest: None.

1 Public Health Laboratory Service. Unlinked anonymous HIV prevalence monitoring programme: England and Wales. Survey of antenatal clinic monttoring programme: England and Wales. Survey of

2 Chrystie IL, Palmer SJ, Kenney A, Banatvala JE. HIV seroprevalence among women attending antenatal clinics in London. Lancet 1991;339:364.

3 Unlinked Anonymous Surveys Steering Group. Unlinked anomymous HIV seroprevalence momitoring programme. London: Department of Health, 1996.

4 Westmorland T. Workshop on political, ethical, legal, and human rights issues confronting implementation of global strategy. International conference on global strategies for the prevention of HIV from mothers to infants. Washington, DC: American Society for Microbiology, Office of AIDS Research, 1997.

5 Boyd KM. HIV infection: the ethics of anonymised testing and of testing pregnant women. Institute of Medical ethics; working party report. J Med Ethics 1990;16:173-8.

(Accepted 10 December 1997)

\title{
Late diagnosis of paediatric HIV infection in south west London
}

\author{
M P Richardson, M Sharland
}

The family clinic at St George's Hospital provides care for HIV positive children throughout south west London. We are increasingly concerned about the late presentation of many children. This is particularly worrying because in 1992 the Department of Health recommended that all women attending antenatal clinics in areas of higher prevalence (such as Greater London) should be offered an HIV test. ${ }^{1}$ If these guidelines had been effective we would have expected most HIV infected children to be recognised in the perinatal period. To assess the scale of the problem we reviewed the method of presentation of vertically infected children in our area.

\section{Patients, methods, and results}

We studied the hospital notes of all children who attended our clinic between 1986 and 1996 and identified 48 children with vertically acquired HIV infection. (None of these children had risk factors for horizontally acquired HIV infection.)

Presentation was defined as perinatal if the child was referred at, or around, the time of birth; asymptomatic if the child was referred after the identification of another infected family member or after the incidental finding of signs suggestive of HIV infection; and symptomatic if the child's initial complaint was a clinical manifestation of HIV infection. Severity of symptoms and immunological status at diagnosis were staged according to the revised CDC classification. ${ }^{2}$ To determine the effect of the Department of Health guidelines, we compared children born before or during $1992(n=24)$ with those born after $1992(n=24)$.

Age at presentation for the whole group ranged from birth to 9 years (median 19 months). The table shows that a significantly higher proportion of children were born in London after $1992\left(5 / 24 v 17 / 24 ; \chi^{2}=\right.$ $2.1, \mathrm{P}<0.001)$. The mode of presentation and disease stage at diagnosis were similar in the two groups $\left(\chi^{2}\right.$ for trend $<1.0, \mathrm{P}>0.2)$. Twenty-three children (48\%; $95 \%$ confidence interval $34 \%$ to $62 \%$ ) presented with infections and $16(33 \% ; 20 \%$ to $46 \%)$ presented with manifestations of organ involvement such as lymphadenopathy and parotitis. On examination, 31 children (65\%; $52 \%$ to $78 \%$ ) had signs of organ involvement.

\section{Comment}

In our area the Department of Health guidelines on antenatal testing have had no effect on the method of presentation of paediatric HIV infection. Since the guidelines were issued in 1992, the mother's HIV infection had been detected by antenatal testing in only one $(6 \%)$ of the 17 children born in London.
See editorial by Mercey

Paediatric Infectious Diseases Unit, St George's Hospital, London SW17 0QT M P Richardson, senior registrar M Sharland, consultant

Correspondence to: Dr Richardson mrichard@sghms.ac.uk

BMJ 1998;316:271-2 